\title{
Comparing Social Knowledge Construction of College English Language Learners in Groups Characterized by Facilitative and Directive Other-Regulation: A Case Study
}

\author{
Ye Tao ${ }^{1} \&$ Yanyan $\mathrm{Li}^{1}$ \\ ${ }^{1}$ School of Educational Technology/Smart Learning Institute, Beijing Normal University, Beijing, China \\ Correspondence: Yanyan Li, School of Educational Technology/Smart Learning Institute, Beijing Normal \\ University, 100875, Beijing, China. Tel: 86-188-1136-9332.
}

Received: June 2, 2020

Accepted: July 1, 2020

Online Published: July 20, 2020

doi:10.20849/jed.v4i2.752

URL: https://doi.org/10.20849/jed.v4i2.752

\begin{abstract}
Many studies have explored the role of regulation of learning in supporting social knowledge construction. Other-regulation is a common regulation type in collaborative learning. However, few studies have examined learners' social knowledge construction in other-regulation groups. This study attempts to provide a new lens to understand the role of regulation of learning in supporting social knowledge construction and broaden our knowledge about two forms of other-regulation within groups. Toward that end, this study compares social knowledge construction in groups characterized by facilitative and directive other-regulation. The two case groups of four in this study were selected from a larger sample $(\mathrm{N}=22)$. Content analysis and sequential analysis were used to analyze the online chat log collected from two groups. The comparison was made in terms of the frequency and behaviour pattern of social knowledge construction between the two groups. Qualitative analysis was adopted to explore the interrelation between social knowledge construction and two forms of other-regulation. Results indicate that the facilitative other-regulation group engaged in more high-level social knowledge construction and demonstrated more continuous and systematic behaviour patterns. Further qualitative analysis reveals that facilitative other-regulation occurred concurrently with social knowledge construction and played a promoting role in this process. In contrast, directive other-regulation followed social knowledge construction but failed to guide the subsequent knowledge construction moves, ending in impeding the ongoing of social knowledge construction smoothly.
\end{abstract}

Keywords: collaborative learning, social knowledge construction, regulation of learning, other-regulation

\section{Introduction}

\subsection{Introduce the Problem}

Theories of social constructivism suggest that new knowledge is constructed through social interaction (Driver et al., 2014; Leach \& Scott, 2000; Lochhead \& Yager, 1996). Social knowledge construction is the core mechanism of collaborative learning, during which students share their ideas, discuss divergent opinions, co-construct new understandings, and reach an agreement. The competence of social knowledge construction is closely related to learning outcomes and performance (e.g., Wang, 2009; Weinberger, Stegmann, \& Fischer, 2007). Research has established that regulation of learning, which refers to monitoring and control intentionally conducted by students during the learning process in order to achieve learning goals (Pintrich, 2004; Su et al., 2018; Zimmerman \& Schunk, 2011), leads to better social knowledge construction (e.g., Chan, 2012; Hmelo-Silver \& Barrows, 2008; Volet, Summers \& Thurman, 2009). In real group activities, it is common for students to experience inequality in regulatory contributions. Other-regulation appears when one or two group member temporarily leads topic and regulates for the entire group (Vauras et al., 2003; Volet, Vauras, \& Salonen, 2009). Although other-regulation is primarily regarded as guiding and instructive (Hardwin \& Oshige, 2011), researchers have identified a second form of other-regulation characterized by controlling and managing (Rogat \& Linnenbrink-Garcia, 2011; Volet \& Mansfield, 2006). These two forms of other-regulation are conceptualized as facilitative and directive other-regulation. The dominant form of other-regulation affects group dynamics and, consequently, leads to different cognitive consequence (Bianchini, 1997; Cohen, 1994). Thus, it is reasonable to assume that social knowledge construction in groups characterized by facilitative or directive other-regulation 
has different characteristics. However, little is known about learners' social knowledge construction in different forms of other-regulation group. Examining how students of different forms of other-regulation groups engage in social knowledge construction extends previous research on the role of regulation of learning in supporting social knowledge construction and broadens our knowledge about how two forms of other-regulation operate in groups. These can further enable us to understand collaborative learning better. For these reasons, this study aims to compare social knowledge construction in groups characterized by facilitative and directive other-regulation.

\section{Literature Review}

\subsection{Regulatory Moves Supporting Social Knowledge Construction}

Regulation of learning is a voluntary, goal-directed, metacognitive activity during which students monitor and control their cognition, emotion, motivation, behaviour in order to achieve their learning goals (Pintrich, 2004; $\mathrm{Su}$ et al., 2018; Zimmerman \& Schunk, 2011). Self-regulation is the first concept proposed based on social-cognitive perspectives, which refers to individual learners actively, intentionally regulate their behaviour and cognition during the learning process (Pintrich, 2000; Zimmerman, 1990). Considering of the contextualized nature and interrelationships in collaborative learning, researchers have drawn on socio-cognitive (Volet, Summers \& Thurman, 2009), socio-cultural (Hardwin \& Oshige, 2011) and situative perspectives (Hadwin \& Järvelä, 2011) to gradually expanded the emphasis from individual self-regulation to social regulation, where group members jointly regulate their shared tasks (Vauras et al., 2003; Volet, Vauras, \& Salonen, 2009). Extensive researches on regulation of learning have been conducted. For example, previous work has differentiated the regulation focus as the task, content understanding, disciplinary practice, group process, and behaviour (A. Lee, O'Donnell, \& Rogat, 2015; Rogat \& Adams-Wiggins, 2014; Rogat \& Linnenbrink-Garcia, 2011; Salonen, Vauras, \& Efklides, 2005; Vauras et al., 2003). Also, researchers have designated regulation sub-processes as planning, goal setting, monitoring, and evaluation (Brown, 1987; Pintrich, 2000; Zimmerman, 2000).

Regulation of learning is considered as a critical factor to ensure learning efficiency (Pintrich, 2004; Salovaara \& Järvelä, 2003; Vauras et al., 2003; Winne \& Perry, 2000). It is suggested that regulation of learning can direct and enhance the productive interactions in social knowledge construction (Chan, 2012; Hmelo-Silver \& Barrows, 2008; Volet, Summers \& Thurman, 2009). Some researches provided empirical evidence for the supporting role of regulation of learning in social knowledge construction within small groups. For example, the study of Lee (2017) indicated that there was a strong connection between co-regulation episodes and categories of questions and statements which could further trigger knowledge construction. The finding of Ucan and Webb's (2015) researches showed that co-regulated planning and monitoring invited group members to participate in constructing knowledge, especially in the early phases of collaboration. Rogat and Linnenbrink-Garcia (2011) concluded that socially shared monitoring maintained collaborative interactions and "sets the stage" for knowledge construction. Besides, the results of Shamaly`s (2019) research highlighted that regulation sub-process of goals setting and progress monitoring contributed significantly to processes of social knowledge construction. It was found that the scope of previous studies on the regulation of learning supporting social knowledge construction have ranged from different regulation types, such as co-regulation and socially shared regulation, different regulation sub-processes, such as planning and monitoring, to different regulation focus, such as content and behaviour. Moreover, these finding showed that some particular regulation type, sub-process and focus play a more important role in the construction of knowledge, such as co-regulation, content monitoring. It is critical to state here that there is an inevitable overlap between social knowledge construction and regulation of content understanding in that they are highly interrelated processes (Rogat \& Linnenbrink-Garcia, 2011; Volet \& Summers, 2013; Volet, Summers \& Thurman, 2009). For example, when a group member requests elaboration, he/she is engaging in content monitoring from the perspective of social regulation, as he/she is evaluating content understanding and providing feedback. From an alternate perspective, this group is at the third level of Gunawardena`s (1997) social knowledge construction framework, where group members engage in negotiating meanings.

\subsection{Facilitative and Directive Other-Regulation in Collaborative Learning}

Researches began to pay attention to who is regulating within the group and assumed that some group members play a wholly instructive role in group activities (Hardwin \& Oshige, 2011; Vauras et al., 2003). Future studies distinguished the range of social regulation from other-regulation, in which one or two group members temporarily take an instructive role in dominating the interaction, guiding activities, and regulating for the group, to socially shared regulation, whereby several group members jointly regulate collaborative activity without specific central members (A. Lee et al., 2015; Rogat \& Linnenbrink-Garcia, 2011; Vauras et al., 2003; Volet, 
Vauras, et al., 2009). Although other-regulation is primarily regarded as one group member taking a facilitative and guiding role in the group regulatory process (Hardwin \& Oshige, 2011), research has distinguished a second form of other-regulation characterized by the attempt of one directive and explicit other-regulator to control and manage others and group processes (Rogat \& Adams-Wiggins, 2014; Rogat \& Linnenbrink-Garcia, 2011; Volet $\&$ Mansfield, 2006). These two forms of other-regulations are respectively conceptualized as facilitative and directive other-regulation.

Previous research has identified some features of other-regulation that distinguish directive from facilitative forms. Rogat and Adams-Wiggins (2014) suggested that facilitative other-regulators' primary aim was to maintain a position of control, while directive other-regulators attempted to produce an improved product that integrated everyone's contributions. Besides, they identified the different regulation focus of facilitative and directive other-regulation. For instance, a facilitative other-regulator paid more attention to content monitoring and conceptual understanding. In contrast, a directive other-regulator was more concerned with superficial details, such as neatness and format (Rogat \& Adams-Wiggins, 2014). Research also examined variation in the participation of group members in the facilitative and directive other-regulation group. Members of the facilitative other-regulation groups may demonstrate balanced or imbalanced participation, although they are provided with equal opportunities to contribute within groups. In contrast, the directive other-regulation group is always related to imbalanced participation (Rogat \& Adams-Wiggins, 2014), which is due to that the directive other-regulator offers few opportunities for other group members to participate by constantly ignoring or rejecting their contributions (Eilam \& Aharon, 2003; Kumpulainen \& Mutanen, 1999; Rogat \& Adams-Wiggins, 2014; Volet \& Mansfield, 2006). Another study conducted by Rogat and Adams-Wiggins (2015) investigated how the socio-emotional process differ for groups characterized by facilitative or directive other-regulation. Their results indicated that members in directive other-regulation groups tended to engage in highly critical and socially comparative discourse, which enabled negative socio-emotional interactions dominant in the group. In contrast, members in facilitative other-regulation groups promoted positive socio-emotional interactions by encouraging widespread participation and showing respect for alternative opinions.

Previous research has examined the role of regulation of learning in supporting social knowledge construction. However, it remains incomplete without a consideration of other-regulation since it is common in real collaborative learning. Besides, despite growing research on distinguishing features of two forms of other-regulation, few studies have linked them to cognitive processes. Accordingly, the purpose of the current study is to bring a new lens to explore the role of regulation of learning in supporting social knowledge construction and broaden our knowledge about facilitative and directive other-regulation in groups, which can further increase our understanding of the dynamic of collaborative learning. Specifically, this study attempt to compared social knowledge construction in two case groups that characterized by facilitative and directive other-regulation. This study is guided by the following two questions:

(1) What differences can be found in social knowledge construction between groups characterized by facilitative or directive other-regulation?

(2) What is the interrelation between social knowledge construction and different forms of other-regulation?

\section{Method}

\subsection{Participant}

Referring to the distinguishing features of facilitative and directive other-regulation proposed in Rogat and Adams-Wiggins`s (2014) study, this study purposefully selected two case groups from a larger sample $(\mathrm{N}=22)$ based on frequency information for participation and regulation and an initial view of groups ' chat content (See 3.4.1 Group selection for more details). Each group contains four college students (aged around 19-20 years old). All students are Chinese and they were assigned to groups according to gender and English proficiency that was tested at the time of admission.

\subsection{Curriculum Context}

This study was conducted in a compulsory English course. In this course, students were scheduled to have a two-hour face-to-face tutorial every week. After the tutorial, students would have one-week time to complete a collaborative writing task online. In this study, the wiki space of Moodle platform was adopted for students to co-edit their writing products. Tencent $\mathrm{QQ}$, an instant messenger tool that has been proved effective in promoting interactions between peers (Zheng \& Yu, 2016), was used for online discussion. One of the collaborative writing activities was selected for this study, the writing topics of which was "Globalization: Threat or Opportunity?". 


\subsection{Data Coding}

The coding scheme for other-regulation was obtained by modifying parts of the coding scheme used in Rogat and Adams-Wiggins (2014) studies (Table 1). According to the coding scheme, the designation of other-regulation needs to consider two aspects. On the one hand, other-regulation is a form of social regulation that is distinguished from content contribution or off-task discussion, referring to metacognitive behaviour, such as planning, monitoring, evaluation, of the group's content understanding, disciplinary practices, group process, etc.. On the other hand, who is regulating in group distinguishes other-regulation, in which one group member regulates for the group, from socially shared regulation, whereby two or more group members equally regulate for the group. Besides, other-regulation is often brief, and sometimes it can be more sustained. Therefore, when we coded across single turns, we will consider its context in order to exclude the situation that this turn belongs to a socially shared regulation episode.

Table 1. Coding scheme for other-regulation

\begin{tabular}{lll}
\hline Code & Description & Example \\
\hline Other-regulation & $\begin{array}{l}\text { One group member regulates "It seems that the analysis of globalization } \\
\text { understanding of content or disciplinary trends have overlapped with the } \\
\text { practice, the task, group process or introduction part." } \\
\text { behaviour for the group. }\end{array}$ & "Now let us discuss the pros and cons." \\
\hline
\end{tabular}

Next, we coded across single turns of the online discussion of the selected facilitative and directive other-regulation groups (See 3.4.1 Group selection for more details) in terms of social knowledge construction. The Interaction Analysis Model (Table 2) was adopted in this study, which was initially developed by Gunawardena (1997).

Table 2. Coding scheme for social knowledge construction

\begin{tabular}{|c|c|c|}
\hline Code & Description & Example \\
\hline $\begin{array}{l}\text { SKC1: Sharing and } \\
\text { comparing information }\end{array}$ & $\begin{array}{l}\text { Statement of observation or } \\
\text { opinion; statement of agreement } \\
\text { between participants }\end{array}$ & $\begin{array}{l}\text { "I think the economy and culture are the } \\
\text { most affected by globalization." }\end{array}$ \\
\hline $\begin{array}{l}\text { SKC2: Discovering } \\
\text { inconsistencies and } \\
\text { contradictions between } \\
\text { opinions }\end{array}$ & Identifying areas of disagreement & $\begin{array}{l}\text { "I think you are off-topic. In the content } \\
\text { you write, the protagonist is no longer } \\
\text { globalization but the Internet." }\end{array}$ \\
\hline $\begin{array}{l}\text { SKC3: } \\
\text { negotiation }\end{array}$ & $\begin{array}{l}\text { Negotiating meanings of terms and } \\
\text { negotiation of the relative weight to } \\
\text { be used for various agreements. }\end{array}$ & $\begin{array}{l}\text { "Here, you confuse the benefits of the } \\
\text { Internet with the benefits of } \\
\text { globalization. Of course, the Internet is a } \\
\text { strong push for globalization, but you } \\
\text { need to make it clearer." }\end{array}$ \\
\hline $\begin{array}{l}\text { SKC4: Testing and } \\
\text { modification }\end{array}$ & 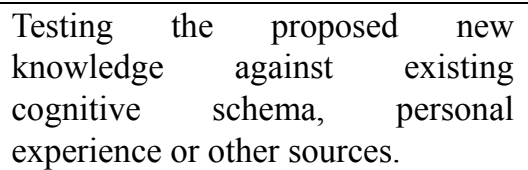 & $\begin{array}{l}\text { "It is better to change the order of the last } \\
\text { two paragraphs." }\end{array}$ \\
\hline $\begin{array}{l}\text { SKC5: Agreement } \\
\text { statement(s) } \text { or } \\
\text { application of newly } \\
\text { constructed meaning }\end{array}$ & $\begin{array}{l}\text { Summarizing agreement and } \\
\text { metacognitive statements that show } \\
\text { new social knowledge construction }\end{array}$ & $\begin{array}{l}\text { "Then, as for what college students } \\
\text { should do, we finally decided to write } \\
\text { from three aspects: First, cultivate the } \\
\text { self-confidence of the nation; second, do } \\
\text { not blindly worship foreign cultures; } \\
\text { third, promote the excellent traditional } \\
\text { culture of the nation." }\end{array}$ \\
\hline
\end{tabular}


Two independent coders coded $15 \%$ of the content after receiving training. Cohen 's Kappa was used to judge the inter-rater reliability and was computed as 0.79 and 0.74 for other-regulation and social knowledge construction, which are acceptable since this coding process contained a higher level of inference (Bakeman \& Gottman, 1997; Ucan \& Webb, 2015). After the two coders discussed and reached a consensus on the inconsistencies, the remaining coding work was completed by one coder.

\subsection{Data Analysis}

\subsubsection{Group Selection}

In the process of group selection, we referred to the features proposed by Rogat and Adams-Wiggins (2014) that distinguish groups characterized by facilitative and directive other-regulation. The participation and regulatory moves for each group member of the 22 groups was calculated. Since the total conversational turns of each group were different, we transformed these counts into percentage.

Firstly, we selected groups demonstrating imbalanced regulatory contribution, which meant there were one or two members in each group had significantly more regulating behaviour compared with their peers. The imbalanced regulatory contribution among group members evidenced the presence of other-regulation.

Although facilitative other-regulation promotes balanced participation, it may yield imbalanced participation when one group member makes efforts to support others (Rogat \& Adams-Wiggins, 2014). Therefore, when selecting potential facilitative other-regulation groups, we ensured that no group member was at a significant disadvantage in participation. The possible situation was that one or two members had higher rates of participation, and the remaining members demonstrated approximately balanced participation. One feature of directive other-regulation was that groups showed a pattern of exclusion of certain group members (Rogat \& Adams-Wiggins, 2014). Groups that demonstrated meagre participation of certain group members were designated as potential directive other-regulation groups.

After identifying the potential facilitative and directive other-regulation groups, we took a closer look at the chat content to accurately screen out the groups characterized by facilitative and directive other-regulation. Previous studies suggested that directive other-regulation groups often show highly critical feedback or repeated neglect and rejection of group members without rationale. The regulation they adopt is controlling, overly detailed, and focuses on exterior details such as the format of the composition. In contrast, facilitative other-regulation groups usually show efforts to solicit every member's contributions and re-engage disengaged group members.

Lastly, we drew on the frequency information for participation and regulation in combination with an initial analysis of groups ' chat content to finalize our selection of case groups characterized by facilitative and directive other-regulation.

\subsubsection{Comparison Between Groups}

In order to compare social knowledge construction within groups characterized by facilitative and directive other-regulation, this study adopted quantitative and qualitative analyses. Firstly, we compared the percentages of different categories of social knowledge construction in two groups. Then, we used the lag sequential analysis to compare the behaviour pattern of the two groups. Lastly, episodes, where social knowledge construction occurs intensively, were selected for qualitative analysis for the interrelation between social knowledge construction and different forms of other-regulation. Specifically, we focus on how other-regulation occurs along with social knowledge construction and what role it plays in this process.

\section{Results}

\subsection{Groups Employing Facilitative and Directive Other-Regulation}

To designate the case groups that characterized by facilitative and directive other-regulation, we drew on the frequency information for participation and regulation, as well as the results of chat content view. Two groups were finally selected. Participation and regulatory moves are described in Table 3 . The imbalanced regulation evidence the presence of other-regulation in both two groups. However, compared with Group 1, Group 2 has more unequal regulation with student $\mathrm{E}$ far exceeding his peers. Both two groups demonstrate imbalanced participation among group members with one single group member shows significantly higher participation than others. In Group 1, Student A takes the lead and the other three show more balanced participation compared with each other. However, in Group 2, there is a student (Student G) excluded from making contributions, showing very limited participation. The frequency data indicates Student A and Student E, with the highest participation and the most frequent regulatory moves are the other-regulators of their groups. 
Table 3. Group balance in participation and regulation

\begin{tabular}{lllll}
\hline & Turns taken & $\begin{array}{l}\text { Participation(\% of total } \\
\text { turns) }\end{array}$ & $\begin{array}{l}\text { Frequency } \\
\text { of regulation } \\
\text { moves }\end{array}$ & $\begin{array}{l}\text { Percentage of } \\
\text { regulation } \\
(\%)\end{array}$ \\
\hline Group 1 & & & 62 & 35.23 \\
\hline Student A & 541 & 44.13 & 35 & 19.89 \\
\hline Student B & 266 & 21.70 & 53 & 30.11 \\
\hline Student C & 222 & 18.11 & 26 & 14.77 \\
\hline Student D & 197 & 16.07 & & \\
\hline
\end{tabular}

\begin{tabular}{lllll}
\hline Group 2 & & & 64 & 57.66 \\
\hline Student E & 353 & 48.42 & 15 & 13.51 \\
\hline Student F & 132 & 18.11 & 14 & 12.61 \\
\hline Student G & 80 & 10.97 & 18 & 16.22 \\
\hline Student H & 164 & 22.50 & \\
\hline
\end{tabular}

Initial analysis of groups' chat content revealed that Group 1 demonstrated some features of facilitative other-regulation, while Group 2 exhibited patterns of directive other-regulation. The findings are described below.

\section{Group 1}

Student A, the other regulator of Group 1, demonstrated the highest participation and regulation counts in the group. During collaboration, he showed great efforts to involve all group members into activity. There was an episode in which one group member said: "My language is not good. I had better not participate in this part of the discussion." Student A regulated his escape behaviour by praise: "Come on. I think you wrote very well before, and it even does not need modification". Besides, when he was making a schedule for group process, he said: "Let us make an appointment for the next discussion. Please tell me your recent schedule, and we need to find a time when everyone is available". Also, he attempted to integrate everyone's opinions by asking students who have not shared for supplementary views. There was additional evidence indicating Student A is a facilitative other-regulator. Some episodes involved Student as attempts to regulate emotion for the group. When group members encountered negative feelings, he would provide reassurance. For example, a classmate felt uneasy, saying, "I am afraid what I have written is too long to meet the requirements." Student A said: "It is OK. Do not worry about that. It leaves room for subsequent deletion and modification." In general, the preliminary analysis of the chat content showed that the other-regulation of Student A did not include highly critical discourse. On the contrary, most of his regulatory moves indicated that he was encouraging extensive participation and including different opinions.

Group 2

In Group 2, Student E, as the other-regulator, performed the most frequent participation and regulation. It seemed that the focus of his regulation was not on supporting the group or improving the task product, but instead putting himself in the central and controlling position. He tended to give instructions directly to group members without soliciting their opinions. For example, when he was assigning group tasks, he said: "There are three parts in total. We have four people, so we are divided into $1+1+2$. The third part is harder to write so that it will be distributed to two people. I will write the first part, and the remaining two parts are up to you. "He sometimes rejected the opinions of other group members with or without rationale. For example, when discussing how to introduce globalization, one group members proposed that "We can introduce globalization with a small thing in daily life." He rejected directly: "No, that is informal." There was another episode in which all other members were discussing how to write about threats, but he seemed impatient, emphasizing: "Do not talk about threats now. Let us discuss the introduction part, the development of globalization." What is more, most of student E's feedback was critical or evaluative. For example, when one group member continuously shared information from the Internet, he said: "Do not always copy and paste, write it yourself." Also, for example, when a member used a certain sentence pattern, he said: "Why do you all like to use the sentence 
'under the tide of ......'? It is too old-fashioned." In short, the preliminary content analysis allows us to see a directive other-regulator who tends to reject, ignore, and criticize.

\subsection{Comparison Between Groups Characterized by Facilitative and Directive Other-Regulation}

The frequency and percentage of social knowledge construction are shown in table 4 . Table 4 shows that, except for SKC1, the percentage of social knowledge construction of each level of Group1 is higher than that of Group 2. This gap is most evident in terms of SKC2 and SKC5 that are almost absent in Group 2. It indicates that students in Group 1 are more motivated to conduct higher-level social knowledge construction. It can also be found that whether in Group 1 or Group 2, SKC3 has the highest percentage and SKC1 also occupies a large proportion, while the rest categories of social knowledge construction (i.e., SKC 2, SKC 4, SKC 5) are relatively limited.

Table 4. Frequency and percentage of students' social knowledge construction in Group 1 and Group 2

\begin{tabular}{|c|c|c|c|c|}
\hline & Group 1 & & Group 2 & \\
\hline & Frequency & Percentage & Frequency & Percentage \\
\hline SKC1: Sharing and comparing information & 111 & 9.05 & 85 & 11.66 \\
\hline $\begin{array}{l}\text { SKC2: Discovering inconsistencies } \\
\text { contradictions between opinions }\end{array}$ & 28 & 2.28 & 4 & 0.55 \\
\hline SKC3: Meaning negotiation & 375 & 30.59 & 99 & 13.58 \\
\hline $\begin{array}{l}\text { SKC4: Testing and modification of proposed } \\
\text { synthesis or co-construction }\end{array}$ & 44 & 3.59 & 17 & 2.33 \\
\hline $\begin{array}{l}\text { SKC5: Agreement statement(s) or application of } \\
\text { newly constructed meaning }\end{array}$ & 43 & 3.51 & 5 & 0.69 \\
\hline
\end{tabular}

The sequential analysis was adopted in order to further compare the sequential behaviour patterns of the two groups. The adjusted residuals table for Group 1 and Group 2 are presented below (Table 5), where the data indicates the $\mathrm{z}$ score values of each sequence. A $\mathrm{z}$ score values greater than 1.96 indicates a significant sequence relationship between the behaviour in the row and the column $(p<0.05)$. Based on these results, a sequence diagram for behaviours that reach the level of significance is depicted in Figure 1 and Figure 2. The arrows in the figure indicate sequence direction. It can be seen from the figure that members of Group 1 shows continuity in every single behaviour. Besides, they tend to negotiate further after they have found differences (SKC2-SKC3). The sequences of SKC4-SKC2 and SKC4-SKC5 indicate that during the modification and testing phase, students tend to put forward different opinions or reach an agreement afterwards. The significant sequences in Group 2 are relatively lack of diversity with SKC3, SKC4, SKC5 in a state of self-circulation, and there is no significant sequence relationship between any two different behaviours.

Table 5. Adjusted residuals Table (Z-scores) for Group 1 and Group 2' social knowledge construction

\begin{tabular}{ccccccccccc}
\hline \multicolumn{7}{c}{ Group 1 } & \multicolumn{7}{c}{ Group 2 } \\
\hline & SKC1 & SKC2 & SKC3 & SKC4 & SKC5 & SKC1 & SKC2 & SKC3 & SKC4 & SKC5 \\
\hline SKC1 & $4.25^{*}$ & -1.09 & -1.6 & -0.06 & -2.43 & 0.81 & 0.38 & -0.36 & -0.99 & -0.03 \\
\hline SKC2 & -2.57 & $2.47^{*}$ & $2.20^{*}$ & -0.78 & -1.51 & 1.43 & -0.28 & -0.9 & -0.6 & -0.32 \\
\hline SKC3 & -2.12 & -1.8 & $5.68^{*}$ & -2.43 & -3.56 & 0.06 & -0.9 & $2.53^{*}$ & -3.57 & -1.24 \\
\hline SKC4 & -0.43 & $2.19^{*}$ & -4.69 & $4.07^{*}$ & $3.55^{*}$ & -1.98 & 1.25 & -3.07 & $8.90^{*}$ & -0.67 \\
\hline SKC5 & 0.12 & 0.79 & -5.37 & 1.18 & $8.06^{*}$ & -0.63 & -0.28 & -0.9 & -0.60 & $6.29^{*}$ \\
\hline
\end{tabular}




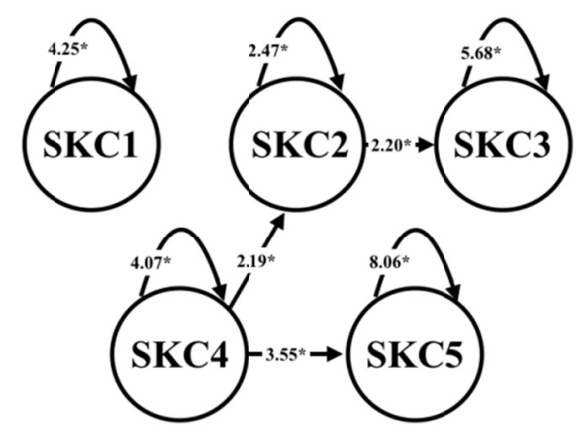

Figure 1. Behavioral sequence of social knowledge construction of Group 1

Description: The arrows in the figure indicate sequence direction. SKC1=Sharing and comparing information. $\mathrm{SKC} 2=$ Discovering and contradictions between opinions. SKC3 $=$ Meaning negotiation. SKC4=Testing and modification of proposed synthesis or co-construction. SKC5=Agreement statement(s) or application of newly constructed meaning.

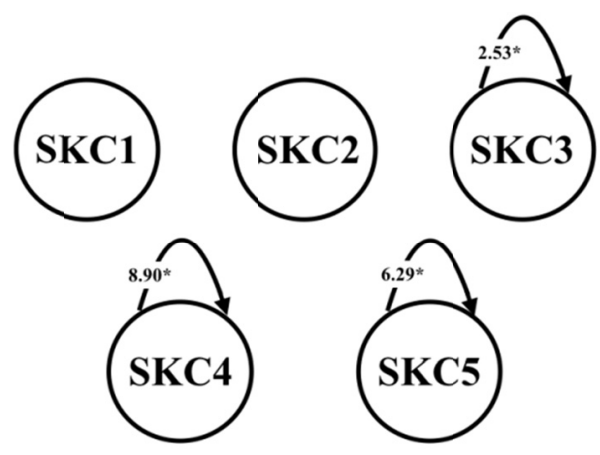

Figure 2. Behavioral sequence of social knowledge construction of Group 2

Description: The arrows in the figure indicate sequence direction. SKC1=Sharing and comparing information. $\mathrm{SKC} 2=$ Discovering and contradictions between opinions. SKC3=Meaning negotiation. SKC4=Testing and modification of proposed synthesis or co-construction. SKC5=Agreement statement(s) or application of newly constructed meaning.

\subsection{Interrelation Between Social Knowledge Construction and Two Forms of Other-Regulation}

In terms of the interrelation between the social knowledge construction and other-regulation, here we give an example respectively from the facilitative and directive other-regulation group to illustrate the results of qualitative analysis.

\section{Group 1}

From the example of Group 1, it can be seen that no one take a dominant role in the contribution of social knowledge construction. The regulation employed by the facilitative other-regulator mainly focuses on group process, behaviour and content. Student A employed regulation to monitor the group progress. For example, he proposed activities that the group should do next (e.g., "I feel that we need to hurry to the next step. Let us discuss how to write about these three aspects."). Student A's behavioural regulation aims at encouraging widespread participation and extensively soliciting and integrating ideas. For example, following the stage summary, he continued to promote opinions (i.e., "What do you think?"). Besides, in this observation, Student D was not confident in his competence and tended to exclude himself from group discussion. Student A prevented such things from happening in a timely behavioural regulation manner alongside praise (i.e., "Come on. I think you wrote very well before, and it even does not need modification."). Further, Student A used content monitoring to facilitate more in-depth knowledge construction, requesting a further explanation and clarification 
when different views appear (i.e., "Is it? Tell us your opinion.").

Student A's facilitative other-regulation was integrated with and served social knowledge construction in their group. It was found that social knowledge construction in Group 1 and Student A`s facilitative other-regulation occur concurrently. These regulatory behaviours carry forward and follow through the process of social knowledge construction, like needles, stitching together group members' contributions to the construction of knowledge. It can be concluded that facilitative other-regulation played a promoting role in the process of social knowledge construction.

A: So, we write about globalization in terms of people, country, and culture. What do you think?

B: I agree.

$C: O k$.

A: I feel that we need to hurry to the next step. Let us discuss how to write about these three aspects.

$C$ : In terms of cultural globalization, we can talk about the issue of cultural diversity.

B: Cultural globalization has made the cultures of all countries blend.

A: I agree. Moreover, this may result in the loss of cultural diversity.

$B$ : But I think the loss of cultural diversity is too absolute.

A: Is it? Tell us your opinion.

$B$ : In the beginning, cultural globalization has increased diversity. Because we have the opportunity to get in touch with the cultures of various countries, in the long run, there is the possibility of cultural assimilation which lead to loss of diversity.

C: Assimilation is the result of cultural integration. The national culture may be assimilated by foreign cultures, so that it loses its characteristics. Is that right?

$B:$ I mean that.

D: My language skills are not excellent, so I will not participate in the discussion.

A: Come on. I think you wrote very well before, and it even does not need modification.

Group 2

From the example of Group 2, it was found that the directive other-regulator Student E mainly focused on the regulation of discipline and content. He rarely paid attention to behavioural regulation, which means that he may fail to encourage widespread participation. Student E conducted extensive discipline supervision in group, judging the source of the arguments provided by other group members. For example, he repeatedly questioned that the ideas provided was not original (e.g., "... you moved directly from the Internet, right?", "Do not always copy and paste, write it yourself."), which may make group members feel disrespected and incompetent. In providing content monitoring, the feedback provided by Student $\mathrm{E}$ was directly critical and evaluative and rarely contains alternative views for considering (e.g., "No, that is informal.", "You are making a conceptual shift."). Besides, Student E regulated content understanding exclusively like giving orders. (e.g., "Do not talk about threats now."). He also attempted to make decisions for the group in his favour. For example, he repeatedly asked the group members to discuss the current development of globalization, obviously disregarding that they were discussing other topics. Student E`s other-regulation was used as a means to gain control rather than increasing common understanding or promoting the widespread participation in the process of social knowledge construction.

Student E's non-euphemistic and disrespectful expression implies that he attempted to construct a power relationship and maintain his central position in collaborative learning. The directive other-regulation led by Student E seems incompatible with social knowledge construction and even disturbing in that the process of contributing ideas and constructing knowledge were often interrupted by controlling or critical regulatory discourse. It was found that directive other-regulation tended to follow social knowledge construction, appearing as criticism or evaluation, but unfortunately cannot promote and guide the subsequent knowledge construction activities. In this light, the directive other-regulation in Group 2 played a role in impeding the ongoing of social knowledge construction smoothly and coherently.

F: Then we discuss the first paragraph: the threat of globalization.

G: Threats can be elaborated from different aspects, such as political, economic and cultural. 
E: No, no, there should be a section to introduce globalization before this.

$G$ : We can introduce globalization with a small thing in daily life.

E: No, that is informal.

F: Globalization is a concept, is also a kind of phenomenon of the human social development process. Globalization refers to the global connections based on the development of human life on a global scale and the rise of global awareness. Countries are interdependent in politics, economic, and trade.

E: Did you write it yourself?

F: Of course not.

E: ... You moved directly from the Internet, right?

F: Yes, but we can process based on this.

H: As a trend of modern economic development, economic globalization has been proved by the fact of world economic development.

E: Why only talk about the economy?

H: when "Economy" is deleted, it also makes sense. For example: Globalization, as a modern trend of social development, has been proved by the fact that the world is developing.

E: You are making a conceptual shift.

$G$ : The threat of globalization can specifically be the weakening of the concept of country and nation, and affecting the patriotism of college students.

E: Is this all written by you, or from the Internet?

G: Copy and paste and appropriate modification.

E: Do not always copy and paste, write it yourself.

H: Because globalization has promoted the rapid development of the Internet, it has provided the possibility for the rapid spread of various cultures, which caused interference for college students to form correct values.

E: I think it is better to make "the current status of globalization" as the introduction part. Do you know how to elaborate it?

F: Therefore, in the wave of globalization, college students should improve their personal qualities and face more vigorous challenges.

E: Do not talk about threats now. Let us discuss the introduction part, the development of globalization. How is it developing now?

H: Regional integration coexists with globalization. I am not sure.

E: Anything else?

\section{Discussion}

Comparison between the groups revealed that the facilitative other-regulation group demonstrated more advanced social knowledge construction than the directive other-regulation group based on the model of Gunawardena (1997). The occurrence of advanced knowledge construction may suggest a high-quality group discussion (Hou, 2011) and a better learning outcome (Barnard et al., 2016; Wang \& Hwang, 2012). The final score on the group task confirmed this prediction. Previous research explained that facilitative other-regulator foster conceptual understanding and idea integration which consequently promotes higher-level social knowledge construction, while directive other-regulators often end in discouraging participation (Rogat \& Adams-Wiggins, 2014). Another distinguishing feature is that the facilitative other-regulation group was more engaged in discovering inconsistencies and contradictions (SKC2) that was very limited in directive other-regulation group. This finding is consistent with the idea that the emergence of critical cognitive processes necessitates a favourable group climate where group members feel safe to provide counter ideas (Baker, 1999; King, 2002). Previous research pointed out that groups characterized by facilitative other-regulation tend to employ positive socio-emotional interactions to foster a favourable group climate (Rogat \& Adams-Wiggins, 2015).

Sequential analysis also revealed that the facilitative other-regulation groups exhibited more continuous and systematic social knowledge construction behaviour during online discussion. The facilitative other-regulation 
groups exhibited a significant sequential pattern between discovering contradictions and negotiating meaning (SKC2-SKC3). Previous studies have indicated that cognitive conflicts can play a positive role in joint activities when group members negotiate these divergent views in informational ways (De Dreu \& Weingart, 2003; Jehn \& Mannix, 2001). The appeal of this sequential pattern may be due to the respect and inclusion of the alternative opinions (Rogat \& Adams-Wiggins, 2015), which promotes the further explanation or clarification of different views. Besides, the facilitative other-regulation groups presented the significant sequence of modifying the proposed product to discovering contradictions or reaching agreement (SKC4-SKC2, SKC4-SKC5). This indicates that during reflection and revision, students would continue to express and negotiate alternative ideas. It is also possible that after modification and testing, they can directly reach final results that everyone is satisfied with. This can be explained that the facilitative other-regulator always try to encourage group members to propose their point views. Therefore, no matter at what stage of collaboration, the group members are provided with abundant opportunities to express different opinions. Similar beneficial sequential patterns were also founded in previous studies (Lin et al., 2016; Yang, Li, \& Xing, 2018). In contrast, the directive other-regulation group showed a lack of continuity in social knowledge construction, tending to perform the same behaviour repeatedly. The findings of the second research question explained that the controlling and highly critical other-regulation in directive other-regulation group could have resulted in them not being motivated to engage in social knowledge construction continuously. To summarize, based on the comparison of frequency and sequential behaviour, directive other-regulation have yielded moderate to moderate-low quality social knowledge construction compared with facilitative other-regulation.

Regarding the second research question, we analyzed the episodes where social knowledge construction occurred intensively. It was found that in the facilitative other-regulation group, other-regulation occurred concurrently with social knowledge construction, carrying forward and following through the process of social knowledge construction. This indicates that the regulatory moves play a promoting role in the construction of knowledge. In contrast, Group 2's case illustrates that directive other-regulation followed social knowledge construction but failed to guide the subsequent knowledge construction activities. Directive other-regulation seems incompatible with social knowledge construction, and even hinders this process. There are several possible reasons for this finding. Firstly, we identified the regulation focus of two groups and found that the regulatory moves exhibited by facilitative other-regulator mainly focus on group process, behaviour and content. In contrast, those of directive other-regulator pay more attention to content and group discipline. Previous research has pointed out the importance of regulation of the group process, indicating that it can facilitate coordinating around meaning-making (Rogat \& Adams-Wiggins, 2014). Behavioural regulation is often used to solicit contributions and promote participation. The lack of behavioural regulation in directive other-regulation group may indicate that the other-regulator ignored the possible non-engagement of the group members, failing in including opinions during social knowledge construction. Although both facilitative and directive other-regulation groups have focused on content monitoring, the directive other-regulation was evaluative and lacked informative feedback, which was not conducive to the continuous processing of social knowledge construction. Secondly, this finding makes sense when we consider the different overarching goals of two forms of other-regulation. In this study, the facilitative other-regulator Students A's regulation intermittently served to request further clarification and re-engage members who were excluded from the discussion. As such, we would make inferences that his regulation aimed at promoting shared understanding and producing improved group products. In the case of student E's directive other-regulation, through providing critical and comparative remarks on other group members' contributions and repeatedly questioning the source of their evidence, this form of other-regulation made group members feel disrespected and incompetent, aiming to construct power relationship where the regulator is in a controlling and central position. This is in line with previous studies which evaluated facilitative other-regulation as aiming at promoting shared understanding, while directive other-regulation as attempting to maintain a position of control (Rogat \& Adams-Wiggins, 2014, 2015).

\section{Conclusion}

The current study extends previous research on the role of regulation of learning in supporting social knowledge construction and broadens our knowledge about how two forms of other-regulation operate within groups. Combining quantitative and qualitative analysis, this study revealed the characteristics of social knowledge construction within groups characterized by facilitative and directive other-regulation, and the interrelation between social knowledge construction and different forms of other-regulation. Besides, referring to the features proposed by Rogat and Adams-Wiggins (2014) that distinguish facilitative and directive other-regulation, this study elaborated the procedure of selecting facilitative and directive other-regulation groups.

Results of this study indicated that when group member do not share opportunities to make contributions, the 
group cannot benefit from the full potential of collaborative learning, which lead to the suffering of learning and learning outcomes (Barron, 2000). These findings have teaching implications for the organization of collaborative learning activities. For example, teachers should take action to prevent students from being excluded in collaboration. Before collaborative activity, teachers can provide students with collaborative skills training and tell them the expectations for ideal collaborative learning. Besides, teachers may structure group interactions and assign roles, in turn requiring students to monitor the discussion process themselves and promptly avoid exclusion of any group member.

The limitation of this research is that it is a case study with limited samples. Although the results of this study provide a reference for us in understanding the role of other-regulation in social knowledge construction, it cannot be regarded as a general conclusion. Besides, the variation of the group's social knowledge construction may also be affected by other factors. We have overlooked some differences, such as personal academic ability, which need further consideration. Future research can expand our sample and explore how to ensure the learning opportunities of each learner in collaborative learning. For example, pedagogical scripts and awareness tools can be designed and adopted in collaborative learning.

\section{Acknowledgements}

This paper was supported by the National Natural Science Foundation of China (grant numbers 61877003), the International Joint Research Project of Faculty of Education of Beijing Normal University, and the 2019 Student Research Fund Project, Faculty of Education, Beijing Normal University.

\section{References}

Bakeman, R., \& Gottman, J. M. (1997). Observing interaction: An introduction to sequential analysis. Cambridge University Press.

Baker, M. J. (1999). Argumentation and constructive interaction. Foundations of Argumentative Text Processing, $5,179-202$.

Barnard, L., Lan, W. Y., To, Y. M., Paton, V. O., \& Lai, S.-L. (2009). Measuring self-regulation in online and blended learning environments. The Internet and Higher Education, 12(1), 1-6.

Barron, B. (2000). Achieving coordination in collaborative problem-solving groups. The Journal of the Learning Sciences, 9(4), 403-436. https://doi.org/10.1207/s15327809jls0904_2

Bianchini, J. A. (1997). Where knowledge construction, equity, and context intersect: Student learning of science in small groups. Journal of Research in Science Teaching: The Official Journal of the National Association for Research in Science Teaching, 34(10), 1039-1065. https://doi.org/10.1002/(sici)1098-2736(199712)34:10<1039::aid-tea5>3.0.co;2-s

Brown, A. (1987). Metacognition, executive control, self-regulation, and other more mysterious mechanisms. Metacognition, Motivation, and Understanding.

Chan, C. K. (2012). Co-regulation of learning in computer-supported collaborative learning environments: A discussion. Metacognition and Learning, 7(1), 63-73. https://doi.org/10.1007/s11409-012-9086-z

Cohen, E. G. (1994). Restructuring the classroom: Conditions for productive small groups. Review of Educational Research, 64(1), 1-35. https://doi.org/10.3102/00346543064001001

De Dreu, C. K., \& Weingart, L. R. (2003). Task versus relationship conflict, team performance, and team member satisfaction: A meta-analysis. Journal of Applied Psychology, 88(4), 741.

Driver, R., Squires, A., Rushworth, P., \& Wood-Robinson, V. (2014). Making sense of secondary science: Research into children's ideas. Routledge.

Eilam, B., \& Aharon, I. (2003). Students' planning in the process of self-regulated learning. Contemporary Educational Psychology, 28(3), 304-334. https://doi.org/10.1016/s0361-476x(02)00042-5

Gunawardena, C. N., Lowe, C. A., \& Anderson, T. (1997). Analysis of a global online debate and the development of an interaction analysis model for examining social construction of knowledge in computer conferencing. Journal of Educational Computing Research, 17(4), 397-431. https://doi.org/10.2190/7mqv-x9uj-c7q3-nrag

Hadwin, A. F., \& Järvelä, S. (2011). Introduction to a special issue on social aspects of self-regulated learning: Where social and self meet in the strategic regulation of learning. Teachers College Record, 113(2), 235-239. 
Hardwin, A., \& Oshige, M. (2011). Self-regulation, coregulation, and socially shared regulation: Exploring perspectives of social in self-regulated learning theory. Teachers College Record, 113(2), 240-264. https://doi.org/10.4324/9780203839010.ch5

Hmelo-Silver, C. E., \& Barrows, H. S. (2008). Facilitating collaborative knowledge building. Cognition and Instruction, 26(1), 48-94. https://doi.org/10.1080/07370000701798495

Hou, H.-T. (2011). A case study of online instructional collaborative discussion activities for problem-solving using situated scenarios: An examination of content and behavior cluster analysis. Computers \& Education, 56(3), 712-719. https://doi.org/10.1016/j.compedu.2010.10.013

Jehn, K. A., \& Mannix, E. A. (2001). The dynamic nature of conflict: A longitudinal study of intragroup conflict and group performance. Academy of Management Journal, 44(2), 238-251.

King, A. (2002). Structuring peer interaction to promote high-level cognitive processing. Theory into Practice, 41(1), 33-39.

Kumpulainen, K., \& Mutanen, M. (1999). The situated dynamics of peer group interaction: An introduction to an $\begin{array}{llll}\text { analytic framework. Learning and } & \text { 4nstruction, }\end{array}$ https://doi.org/10.1016/s0959-4752(98)00038-3

Leach, J., \& Scott, P. (2000). Children's thinking, learning, teaching and constructivism. Good Practice in Science Teaching: What Research Has to Say, 41-56.

Lee, A., O’Donnell, A. M., \& Rogat, T. K. (2015). Exploration of the cognitive regulatory sub-processes employed by groups characterized by socially shared and other-regulation in a CSCL context. Computers in Human Behavior, 52, 617-627. https://doi.org/10.1016/j.chb.2014.11.072

Lee, L., Lajoie, S. P., Poitras, E. G., Nkangu, M., \& Doleck, T. (2017). Co-regulation and knowledge construction in an online synchronous problem based learning setting. Education and Information Technologies, 22(4), 1623-1650. https://doi.org/10.1007/s10639-016-9509-6

Lin, C.-L., Hou, H.-T., \& Tsai, C.-C. (2016). Analyzing the social knowledge construction and online searching behavior of high school learners during a collaborative problem solving learning activity: A multi-dimensional behavioral pattern analysis. The Asia-Pacific Education Researcher, 25(5-6), 893-906. https://doi.org/10.1007/s40299-016-0317-y

Lochhead, J., \& Yager, R. E. (1996). Is science sinking in a sea of knowledge?. A theory of conceptual drift, Science/Technology/Society as Reform in Science Education, 25-38.

Pintrich, P. R. (2000). The role of goal orientation in self-regulated learning. In Handbook of self-regulation (pp. 451-502). Elsevier.

Pintrich, P. R. (2004). A conceptual framework for assessing motivation and self-regulated learning in college students. Educational Psychology Review, 16(4), 385-407. https://doi.org/10.1007/s10648-004-0006-x

Rogat, T. K., \& Adams-Wiggins, K. R. (2014). Other-regulation in collaborative groups: Implications for regulation quality. Instructional Science, 42(6), 879-904.

Rogat, T. K., \& Adams-Wiggins, K. R. (2015). Interrelation between regulatory and socioemotional processes within collaborative groups characterized by facilitative and directive other-regulation. Computers in Human Behavior, 52, 589-600. https://doi.org/10.1016/j.chb.2015.01.026

Rogat, T. K., \& Linnenbrink-Garcia, L. (2011). Socially shared regulation in collaborative groups: An analysis of the interplay between quality of social regulation and group processes. Cognition and Instruction, 29(4), 375-415. https://doi.org/10.1080/07370008.2011.607930

Salonen, P., Vauras, M., \& Efklides, A. (2005). Social interaction-what can it tell us about metacognition and coregulation in learning?. European Psychologist, 10(3), 199-208. https://doi.org/10.1027/1016-9040.10.3.199

Salovaara, H., \& Järvelä, S. (2003). Student' strategic actions in computer-supported collaborative learning. Learning Environments Research, 6(3), 267-284.

Shamaly, A. N. C., Juan, C. C. R., \& Esperanza, V. H. (2019). Knowledge construction and regulation of learning in asynchronous collaborative tasks. Apertura, 11(1), 6-23.

Su, Y., Li, Y., Hu, H., \& Rosé, C. P. (2018). Exploring college English language learners' self and social regulation of learning during wiki-supported collaborative reading activities. International Journal of 
Computer-Supported Collaborative Learning, 13(1), 35-60. https://doi.org/10.1007/s11412-018-9269-y

Ucan, S., \& Webb, M. (2015). Social regulation of learning during collaborative inquiry learning in science: How does it emerge and what are its functions?. International Journal of Science Education, 37(15), 2503-2532. https://doi.org/10.1080/09500693.2015.1083634

Vauras, M., Iiskala, T., Kajamies, A., Kinnunen, R., \& Lehtinen, E. (2003). Shared-regulation and motivation of collaborating peers: A case analysis. Psychologia, 46(1), 19-37. https://doi.org/10.2117/psysoc.2003.19

Volet, S., \& Mansfield, C. (2006). Group work at university: Significance of personal goals in the regulation strategies of students with positive and negative appraisals. Higher Education Research \& Development, 25(4), 341-356. https://doi.org/10.1080/07294360600947301

Volet, S., \& Summers, M. (2013). Interpersonal regulation in collaborative learning activities: Reflections on emerging research methodologies. In Interpersonal regulation of learning and motivation (pp. 218-234). Routledge.

Volet, S., Summers, M., \& Thurman, J. (2009). High-level co-regulation in collaborative learning: How does it emerge and how is it sustained?. Learning and Instruction, 19(2), 128-143.

Volet, S., Vauras, M., \& Salonen, P. (2009). Self-and social regulation in learning contexts: An integrative perspective. Educational Psychologist, 44(4), 215-226. https://doi.org/10.1080/00461520903213584

Wang, Q. (2009). Design and evaluation of a collaborative learning environment. Computers \& Education, 53(4), 1138-1146. https://doi.org/10.1016/j.compedu.2009.05.023

Wang, S.-L., \& Hwang, G.-J. (2012). The role of collective efficacy, cognitive quality, and task cohesion in computer-supported collaborative learning (CSCL). Computers \& Education, 58(2), 679-687. https://doi.org/10.1016/j.compedu.2011.09.003

Weinberger, A., Stegmann, K., \& Fischer, F. (2007). Knowledge convergence in collaborative learning: Concepts and assessment. Learning and Instruction, 17(4), 416-426. https://doi.org/10.1016/j.learninstruc.2007.03.007

Winne, P. H., \& Perry, N. E. (2000). Measuring self-regulated learning. In Handbook of self-regulation (pp. 531-566). Elsevier.

Yang, X., Li, J., \& Xing, B. (2018). Behavioral patterns of knowledge construction in online cooperative translation activities. The Internet and Higher Education, 36, 13-21. https://doi.org/10.1016/j.iheduc.2017.08.003

Zheng, L., \& Yu, J. (2016). Exploring the behavioral patterns of co-regulation in mobile computer-supported collaborative learning. Smart Learning Environments, 3(1), 1. https://doi.org/10.1186/s40561-016-0024-4

Zimmerman, B. J. (1990). Self-regulated learning and academic achievement: An overview. Educational Psychologist, 25(1), 3-17. https://doi.org/10.1207/s15326985ep2501_2

Zimmerman, B. J. (2000). Attaining self-regulation: A social cognitive perspective. In Handbook of self-regulation (pp. 13-39). Elsevier.

Zimmerman, B. J., \& Schunk, D. H. (2011). Self-regulated learning and performance: An introduction and an overview. In Handbook of self-regulation of learning and performance (pp. 15-26). Routledge.

\section{Copyrights}

Copyright for this article is retained by the author(s), with first publication rights granted to the journal.

This is an open-access article distributed under the terms and conditions of the Creative Commons Attribution license (http://creativecommons.org/licenses/by/4.0/). 